\title{
Swallowing in Patients with Mental Disability - Analysis of 189 Swallowing Video Endoscopies
}

\author{
Sulene Pirana ${ }^{1,2,3}$ Marcela Oliveira ${ }^{1}$ Fabiana Pissini ${ }^{1}$ Raíssa Andrade ${ }^{2}$ \\ ${ }^{1}$ Department of Otorhinolaringology, Hospital Universitário São \\ Francisco de Assis, Bragança Paulista, SP, Brazil \\ 2 Faculty of Medicine, Universidade São Francisco, Bragança Paulista, \\ SP, Brazil \\ 3 Universidade Federal de Alfenas, Alfenas, MG, Brazil \\ Address for correspondence Raíssa Andrade, Medical Student, \\ Universidade São Francisco, Bragança Paulista, SP, Brazil, Avenida São \\ Francisco de Assis, 333, Apartamento 03, Lagos de Santa Helena, \\ Bragança Paulista, SP, Brasil CEP: 12916-350
}

Int Arch Otorhinolaryngol 2019;23:25-30.

\begin{abstract}
Keywords

- deglutition disorders

- mentally disabled persons

- video endoscopy

Introduction Feeding, swallowing and breathing are fundamental activities for the survival and well-being of humans; these functions are performed by the most complex neuromuscular unit of the human body, which, when altered, may raise morbidity and mortality rates.

Objective To evaluate deglutition in patients with mental disability in order to determine the incidence and the severity of dysphagia.

Methods A total of 189 institutionalized adult patients with mental disability were analyzed using a $3.2 \mathrm{~mm}$ flexible fiberscope (Machida, Japan 1995). The following food consistencies were tested: pasty, thickened liquid and liquid.

Results Among the total of 189 patients, 101 (53.4\%) were female aged between 14 and 55 years old. Most of them 120 (63.5\%) had profound mental deficiency, 58 (30.7\%) had severe mental deficiency, 9 (4.8\%) had moderate mental deficiency, and 2 (1.1\%) had mild mental deficiency. Gender and the degree of mental deficiency did not influence significantly the degree of dysphagia. Age, degree of disability and interaction between age groups and degrees of disability influenced significantly the degree of dysphagia. Younger patients are more likely to present more severe dysphagia. Stabilization occurs between 31 and 40 years of age, and above this age, a greater chance of less severe dysphagia, because the increase in the degree of mental deficiency decreases the probability of more severe dysphagia.

Conclusion The population that mostly presented severe dysphagia was characterized by being mostly female, with profound mental deficiency, with an average age of 36.7 years. There was no relationship between gender and the degree of mental disability concerning the degree of dysphagia.
\end{abstract}

\section{Introduction}

Feeding, deglutition and breathing are fundamental activities for the survival and well-being of humans, and, once altered, they may raise morbidity and mortality rates. Feeding comprises a set of systems, from choosing the food up to its insertion in the oral cavity, chewing and swallowing. Patients with physical or mental disabilities deviate from this set of systems, leading to a possible compromise of their feeding pattern. ${ }^{1}$

The deglutition process involves bone, muscle, cartilaginous and neural structures of the digestive and breathing tracts, working in a coordinated manner to send the food bolus down to the stomach. Any kind of imbalance in this mechanism may lead to impairments of its function. This process can be divided into four stages: preoral, oral (or received

December 20, 2017

accepted

April 21, 2018

published online

July 25, 2018
DOI https://doi.org/

10.1055/s-0038-1660775. ISSN $1809-9777$.
Copyright $\odot 2019$ by Thieme Revinter

Publicações Ltda, Rio de Janeiro, Brazil
License terms

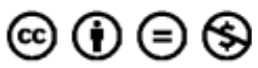


transport), pharyngeal and esophageal. The first two stages are voluntary, while the pharyngeal and esophageal stages are involuntary. ${ }^{2}$

The act of swallowing is a vital function to human beings. Despite the fact that it seems simple, it is a highly complex and dynamic process, whose involved structures and systems are akin to the act of breathing, thus being of extreme importance for the nutrition of the organism as a whole. During deglutition, the food is transported from the oral cavity down to the stomach, without the entry of any substance into the airways, and for that the individual must have precise coordination, mainly between the oral and pharyngeal stages. ${ }^{3}$

Dysphagia is defined as difficulty in swallowing the ingested food in the path from the orophrarynx down to the stomach, which may be associated with other symptoms, such as regurgitation, tracheobronchial aspiration, retrosternal pain, pyrosis, hoarseness, hiccups and odynophagia, and can compromise clinical, nutritional and/or social aspects of the individual. It occurs whenever there is a lack of control in the coordination of the breathing and feeding functions, and may occur as a result of neurological alterations, either congenital or acquired, structural or functional, or even as a result of morbid states. ${ }^{4}$

The broader definition of dysphagia includes abnormalities in all behavioral, sensory and preliminary motor skills involved in the swallowing processes, as well as the cognitive conscience, the visual recognition of food, and the physiological response to the presence of food, such as the increase in salivation, which lead to the desire and capacity of the patients to feed. Additionally, it is a multidimensional symptom commonly dependent on morbidity, mortality and cost. ${ }^{5}$

Dysphagia symptoms may vary from individual to individual and over time in the same person. An important clinical sign is aspiration, defined as the passage of material below the level of the vocal folds, which is an important sign due to several reasons, including the impact it might have on the health of the individual. However, aspiration effects are hard to predict, as they do not equally affect all dysphagic individuals. $^{6}$

It is estimated that, in the United States, between 300,000 and 600,000 individuals with neurological diseases are annually affected by oropharyngeal dysphagia (OD), generally patients with cerebrovascular diseases. Among these, 43 to $54 \%$ will suffer with episodes of tracheal aspiration, $37 \%$ will develop pneumonia, and $3.8 \%$ will die as a consequence of these episodes. ${ }^{7}$

The assessment of dysphagia may be performed using the clinical history of the patient with the aid of complementary examinations, such as videofluoroscopy, surface electromyography, pharyngoesophageal manometry, nasofibrolaryngoscopy and functional endoscopic evaluation of swallowing. These examinations aid in the identification of the cause behind the dysphagia, aspiration risks and oral feeding conditions by establishing the final diagnosis and the most correct therapeutic conduct. $^{4}$

In 1998, the first description of the fiberoptic endoscopic evaluation of swallowing (FEES) procedure was published. Before the advent of optic fiber technology, the laryngoscopy was performed with a mirror or direct invasive laryngoscopic instruments. This evolution changed the practice of laryngoscopy, thus allowing a transnasal approach with a conscious patient during the procedure and providing a vision of the vocal folds during natural speech. ${ }^{8}$

Nasofibrolaryngoscopy and the functional endoscopic evaluation of swallowing provide information regarding the airway structures and the swallowing process, also providing a safe way to administer food to observe the propulsion process of the food bolus. ${ }^{9}$

The objective of the present study was to assess swallowing in institutionalized patients with mental disability to determine the incidence and severity of dysphagia in this population. As specific objectives, it was aimed to characterize the correlation with dysphagia of degree of mental incapacity; and to correlate the degree of dysphagia with the mental deficiency, age group, gender and population studied.

\section{Method}

The present study was approved by the Ethics in Research Committee under the CAAE number 0121.0.132.000-09.

This was a cross-sectional study that analyzed 189 institutionalized adult patients with mental disabilities and associated physical disabilities.

The subjects underwent a previous neuropsychological evaluation for mental disabilities, which was performed by a multidisciplinary team. The disabilities were classified as profound, severe, moderate and mild, according to the World Health Organization's (WHO) International Statistical Classification of Diseases and Related Health Problems, tenth revision (ICD-10).

In the present study, swallowing was analyzed by means of the functional evaluation of swallowing using a Machida $3.2 \mathrm{~mm}$ flexible nasal fiberscope (Machida Endoscope Co., Ltd., Chiba, Japan) without topic anesthesia, in order to preserve sensitivity.

The consistency of the following types of foods was tested: pasty, thickened fluid and fluid. In order to better visualize the food inside the pharynx during and after swallowing, a blue methylene dye was used. All patients were tested with 5 swallowings for each consistency, starting with $5 \mathrm{ml}$ and gradually increasing to 10 and $15 \mathrm{ml}$.

The following were observed: accumulation of saliva or food in the hypopharynx, nausea and coughing reflexes, precocious escape (escape of food to the vallecula and pyriform sinus before actual swallowing), laryngeal penetration (entry of material inside the laryngeal vestibule above the vocal folds) and tracheal aspiration (passage of material below the vocal folds).

The degree of dysphagia was classified according to the clinical endoscopic classification for dysphagia: ${ }^{10}$

Normal swallowing (degree 0): normal swallowing without observable alteration during the examination. Normal oral containment, observable reflexes, no stasis of saliva, food and aspiration, less than three propulsion attempts to clear the food bolus. 
Swallowing in Patients with Mental Disability Pirana et al. 27

Mild dysphagia (degree 1): small post-swallowing stasis, less than three propulsion attempts to clear the food bolus, no nasal regurgitation and laryngeal penetration.

Moderate dysphagia (degree 2): moderate salivary stasis, higher postswallowing stasis, more than three propulsion attempts to clear the food bolus, nasal regurgitation, reduction of laryngeal sensitivity with penetration in the laryngeal vestibule, but without laryngotracheal aspiration.

Severe dysphagia (degree 3): major salivary stasis, considerable worsening of postswallowing residues, poor or no propulsion, nasal regurgitation, tracheal aspiration.

A statistical analysis was performed for tests with significance level, ordinal logistic regression (LR) analysis and odds ratio (OR).

\section{Results}

The studied group consisted of a total of 189 patients, 101 (53.4\%) of which were female. The age of the patients ranged from 14 to 55 years old, with an average age of 36.7 years ( \pm 9.6 years).

Most patients 120 (63.5\%) had profound mental disability, $58(30.7 \%)$ had severe disability, 9 (4.8\%) had moderate disability, and $2(1.1 \%)$ had mild disability. Considering that only 2 patients had a mild degree of disability and that 9 patients had a moderate degree of disability, a new category was created, called "mild or moderate disability", considering those 11 patients (5.8\%), to better visualize the results and the validity of the statistical analysis.

Most of the patients 169 (89.4\%) presented dysphagia: 103 (54.5\%) were severe cases, 46 (24.3\%) were moderate cases, and 20 (10.6\%) were mild cases (-Tables 1, 2 and 3).

According to the ordinal LR analysis, we observed that gender and degree of mental disability $(p=0.450)$ did not

Table 1 Distribution of the degree of dysphagia by gender

\begin{tabular}{|l|l|l|l|l|}
\hline \multirow{2}{*}{ Degree of dysphagia } & \multicolumn{2}{|l|}{ Male } & \multicolumn{2}{l|}{ Female } \\
\cline { 2 - 5 } & $\mathbf{n}$ & $\%$ & $\mathbf{n}$ & $\%$ \\
\hline Severe & 46 & 52.3 & 57 & 56.5 \\
\hline Moderate & 22 & 25.0 & 24 & 23.8 \\
\hline Mild & 12 & 13.6 & 8 & 7.9 \\
\hline Normal & 8 & 9.1 & 12 & 11.9 \\
\hline
\end{tabular}

Table 3 Distribution of the degree of dysphagia by degree of mental disability

\begin{tabular}{|l|l|l|l|l|l|l|}
\hline $\begin{array}{l}\text { Degree of } \\
\text { mental } \\
\text { disability }\end{array}$ & \multicolumn{2}{|l|}{$\begin{array}{l}\text { Mild or } \\
\text { Moderate }\end{array}$} & \multicolumn{2}{l|}{ Severe } & \multicolumn{2}{l|}{ Profound } \\
\hline $\begin{array}{l}\text { Degree of } \\
\text { dysphagia }\end{array}$ & $\mathbf{n}$ & $\%$ & $\mathbf{n}$ & $\%$ & $\mathbf{n}$ & $\%$ \\
\hline Severe & 6 & 50.0 & 30 & 51.7 & 67 & 55.8 \\
\hline Moderate & 3 & 0.0 & 16 & 27.6 & 27 & 22.5 \\
\hline Mild & 0 & 0.0 & 5 & 8.6 & 15 & 12.5 \\
\hline Normal & 2 & 50.0 & 7 & 12.1 & 11 & 9.2 \\
\hline
\end{tabular}

present a significant influence in the level of dysphagia (-Table 4).

Age presented a significant influence in the level of dysphagia $(p=0.024)$, and with the increase in age there was an increase in the severity of dysphagia among the age groups between 10 and 30 years old. The estimated OR was of 0.74 , that is, the increase in age group (from 10-20 years to 21-30 years, for example) increases by $27 \%$ the odds of a patient presenting a more severe level of dysphagia.

The joint influence of three variables was evaluated (gender, age group and degree of disability), and the interactions were assessed in pairs regarding the three variables at the dysphagia level. Gender still had no significant influence on the degree of dysphagia. The same applies to interactions between gender and age, and between gender and mental disability.

We observed that the age group ( $p=0.039)$, the degree of disability $(p=0.024)$ and the interaction between age group and the degree of disability ( $p=0.012$ ) presented a significant influence on the level of dysphagia (-Table 2 ).

The effects of the interaction between age groups and the degree of disability in the probability of presenting more or less severe dysphagia are shown in - Fig. 1. For the age groups between 10 and 20 years old and between 21 and 30 years old, the probability of presenting a more severe dysphagia increased with the increase in the degree of disability. For the age group between 31 and 40 years old, the degree of disability did not affect the level of dysphagia. On the other hand, for the age groups between 41 and 50 years old and between 51 and 55 years old, the result is the opposite. The increase in the degree of disability decreased the odds of presenting a more severe dysphagia.

Table 2 Distribution of the degree of dysphagia by age groups

\begin{tabular}{|c|c|c|c|c|c|c|c|c|c|c|}
\hline \multirow[t]{2}{*}{ Degree of dysphagia } & \multicolumn{2}{|c|}{$\begin{array}{l}\text { 10-20 years } \\
\text { old }\end{array}$} & \multicolumn{2}{|c|}{$\begin{array}{l}21-30 \text { years } \\
\text { old }\end{array}$} & \multicolumn{2}{|c|}{$\begin{array}{l}31-40 \text { years } \\
\text { old }\end{array}$} & \multicolumn{2}{|c|}{$\begin{array}{l}41-50 \text { years } \\
\text { old }\end{array}$} & \multicolumn{2}{|c|}{$\begin{array}{l}51-55 \text { years } \\
\text { old }\end{array}$} \\
\hline & $n$ & $\%$ & $n$ & $\%$ & $n$ & $\%$ & $n$ & $\%$ & $n$ & $\%$ \\
\hline Severe & 6 & 66.7 & 28 & 66.7 & 35 & 54.7 & 27 & 42.8 & 7 & 63.7 \\
\hline Moderate & 1 & 11.1 & 10 & 23.8 & 16 & 25.0 & 17 & 27.0 & 2 & 18.2 \\
\hline Mild & 0 & 0.0 & 2 & 4.8 & 6 & 9.4 & 12 & 19.0 & 0 & 0.0 \\
\hline Normal & 2 & 22.2 & 2 & 4.8 & 7 & 10.9 & 7 & 11.1 & 2 & 18.2 \\
\hline
\end{tabular}


Table 4 Results of ordinal logistic regression models

\begin{tabular}{|l|l|l|l|l|l|}
\hline Model & Variable & Value & Standard error & $p$-value & Odds ratio \\
\hline Gender & Gender & 0.070 & 0.261 & 0.788 & 1.07 \\
\hline Age range & Age range & -0.305 & 0.135 & 0.024 & 0.74 \\
\hline Degree of disability & Degree of disability & -0.65 & 0.128 & 0.450 & 0.85 \\
\hline \multirow{2}{*}{$\begin{array}{l}\text { Age range, degree of disability, } \\
\text { and interaction }\end{array}$} & Age range & 1.326 & 0.642 & 0.039 & 3.77 \\
\cline { 2 - 6 } & Degree of disability & 1.857 & 0.822 & 0.024 & 6.41 \\
\cline { 2 - 5 } & Interaction & -0.626 & 0.249 & 0.012 & 0.53 \\
\hline
\end{tabular}

Regarding the OR:

- At the age group between 10 and 20 years old, the odds of presenting a more severe dysphagia is 3.4 times higher when the degree of disability changes from mild or moderate to severe, and 11.1 times higher when it changes from mild or moderate to profound.

- Between 21 and 30 years old, the odds of presenting a more severe dysphagia is 1.8 times (80\%) higher when the degree of disability changes from mild or moderate to severe, and 3.3 times higher when it changes from mild or moderate to profound.

- At the age group between 31 and 40 years old, the odds of presenting a more severe dysphagia remains practically unaltered when the degree of disability changes from mild or moderate to severe, and from mild or moderate to profound.

- Between 41 and 50 years old, the odds of presenting a more severe dysphagia is 1.9 times higher when the degree of disability changes from mild or moderate to severe, and 3.65 times higher when it changes from mild or moderate to profound.
- At the age group between 51 and 55 years old, the odds of presenting a more severe dysphagia is 3.57 times higher when the degree of disability changes from mild or moderate to severe, and 12.76 times higher when it changes from mild or moderate to profound.

\section{Discussion}

Hospitalized patients with neurological alterations, neurodegenerative diseases, head and neck anatomic alterations, and/or breathing impairments have a higher risk of developing OD. 4

Concerning the feeding and nutrition of patients with special needs, few studies can be found in the relevant literature. It is known that between 39 and $56 \%$ of the children with chronic development issues, such as cerebral palsy (CP), Down syndrome and others, have or will develop a swallowing disorder. The consequences of these disorders end up leading to new health problems that aggravate the conditions of these individuals and their capacity to adapt socially. ${ }^{11}$

The basic motor difficulty of these children may also affect the oral function, understood as the motor and sensory

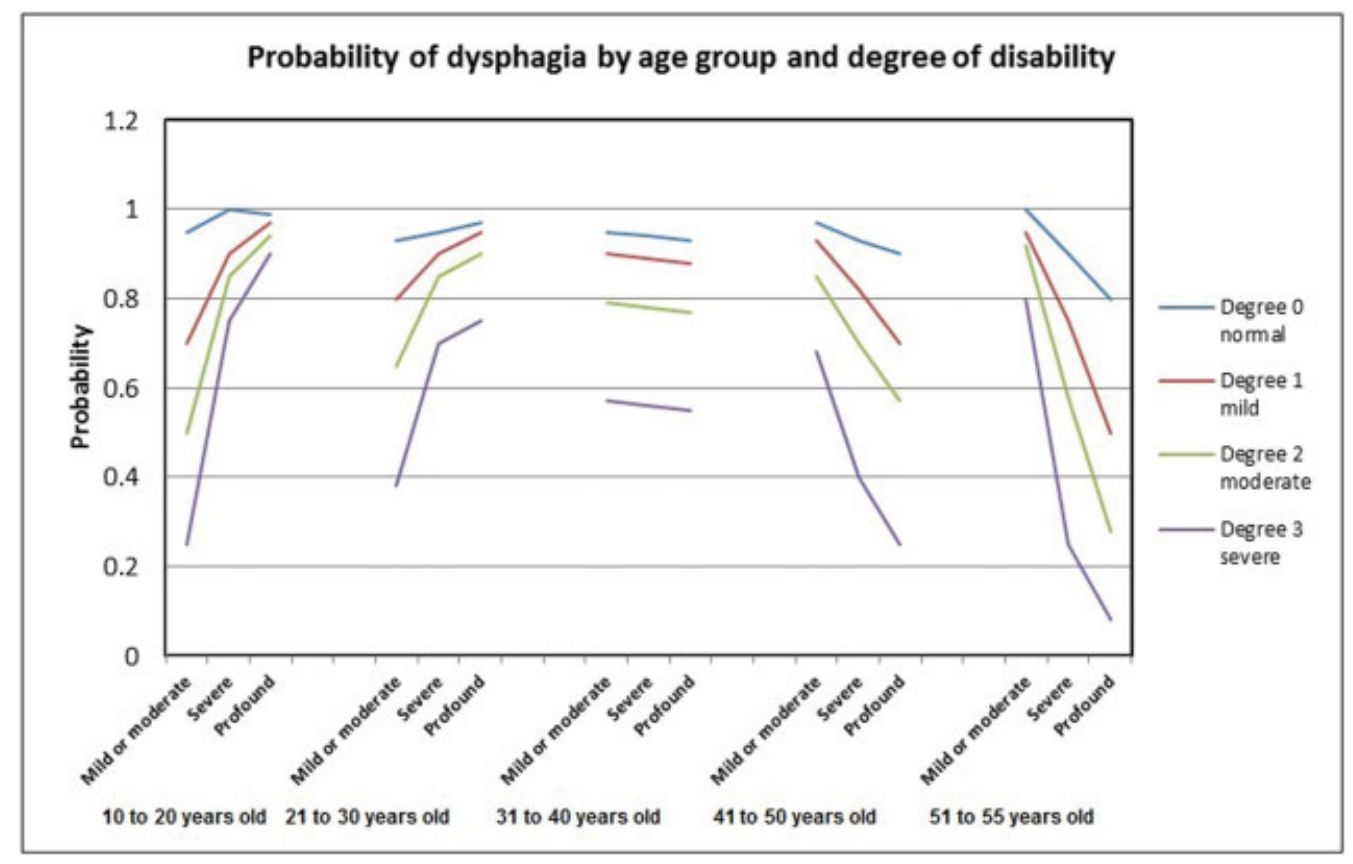

Fig. 1 Probability of dysphagia by age group and degree of disability. 
aspects of the oral cavity and pharynx structures up to the entrance of the esophagus. Therefore, it is known that these children belong to a risk group when developing swallowing disorders or dysphagia, which is one of the first signs of a neurological disorder. ${ }^{11}$

In patients with $\mathrm{CP}$, there is a reduction in cerebral oxygenation, impairing areas that command the swallowing action. Changes in the swallowing action may cause feeding impairments. One of the difficulties found in dysphagia is the act of starting a correct swallowing, as well as others, such as nasal regurgitation, lack of coordination in tongue control, sialorrhea, lack of mobility in the laryngeal muscles, and undesired events such as choking and coughing during meals, which may lead to cases of malnutrition, dehydration and breathing problems. The role of chewing is not significant in these patients, due to foods being swallowed whole, increasing the amount of energy spent in the digestion of each meal. Thus, feeding with solid food is not the most recommended form for most patients with motor and mental disorders. ${ }^{2}$

Performance conflicts in the motor and oral functions may lead to the appearance of inabilities in each step of the swallowing procedure, with possible simultaneous interactions. Chronic swallowing adulterations may lead to malnutrition, dehydration, aspiration and pneumonia. Frequent signs observed in these cases are regurgitation, difficulty to swallow saliva, coughing at the time of feeding, and breathing instability or apnea, among others, which may cause the inability to eat certain types of food. A considerable amount of time must be spent on feeding, and a special diet, different from the one consumed by the rest of the family, is required. These symptoms end up causing stress and anxiety to the parents, turning the act of eating into a complex, difficult, stressful and unpleasant process. ${ }^{11}$

The usage of the concept of efficiency in OD must be understood as the capacity that a therapeutic process has to produce beneficial effects in the dynamics of swallowing. However, the efficiency is related to improvements in the overall status of the individual, regardless of the permanence of the disorder, provided that procedures are implemented to ensure a safe oral ingestion, the maintenance of the nutritional condition, and the stabilization of pulmonary problems. ${ }^{12}$

To monitor OD, it is absolutely required to proceed to the clinical evaluation of the swallowing associated with a videofluoroscopic or nasofibrolaryngoscopic instrumental assessment of swallowing. ${ }^{13}$

In cases in which the neurological impairment is just mild, we can be observe that the oral and motor disorders are generally restricted to the oral stage of swallowing, with no impact on the overall clinical status. Thus, the rehabilitation of functional patterns required for both speaking and swallowing is more easily achieved. However, when the degree is either moderate or severe and there are intense motor, global and oral alterations commonly associated with the presence of multiple disabilities, a situation of dysphagia may appear, added to the alterations of the pathology. ${ }^{7}$

The incidence and severity of OD tend to worsen as the individual ages, and in a much more aggravated manner in those individuals with neurological diseases, thus deterior- ating both the nutritional and breathing states, leading to malnutrition, pneumonia and even death. ${ }^{2}$

We observed in the present study that gender did not affect the severity of the dysphagia.

In the present study, we observed that the interaction between age group and degree of disability presented a significant influence in the level of dysphagia. It became clear that the younger patients have higher odds of presenting a more severe dysphagia. Stabilization occurs between 31 and 40 years old, and after this age the patients present higher odds of having a less severe dysphagia.

The analysis demonstrated that with the increase in the degree of disability, the level of dysphagia increased as well, except for patients between 41 and 55 years old, in whom the increase in the degree of disability decreased the odds of incidence of a more severe dysphagia. We can infer that the patients with more severe dysphagia do not reach the older age groups due to breathing complications, which allows us to understand that, at older age groups, we find patients with a milder dysphagia.

The analysis of dysphagia in patients with cerebral palsy is intended to warn the medical staff of the requirement of a more individualized and customized treatment of the patient, to promote more quality and functionality to the life of the patient.

Dysphagia is a symptom that involves several anatomic and functional alterations, which must be addressed in a multidisciplinary manner. Several fields of expertise in the field of health must work together to ensure the evaluation and the access to all factors surrounding the issue, as well as take the required actions that enable the control of the dysfunction, thus preventing potential complications, such as malnutrition, dehydration and aspiration pneumonia. ${ }^{14}$

The patient who is clinically impaired by dysphagia still in the hospital environment requires treatment from a multidisciplinary team formed by a speech therapist, physicians from different areas of expertise, a physiotherapist, a nutritionist, a nurse, an occupational therapist, and a psychologist. ${ }^{15}$

Dysphagia remains an important symptom with a poorly defined epidemiology. Some studies suggest a prevalence rate between 16 and $22 \%$. Other studies state that dysphagia will become an important public health issue with increasing age. There are few studies available on the impact of dysphagia on the quality of life of the patients. ${ }^{16}$

The diagnosis and treatment of dysphagia have the potential to decrease the morbidity and mortality rates of patients with mental disability.

\section{Conclusion}

The study sample was characterized as mostly female, with profound mental disability, with an average age of 36.7 years, and $89.4 \%$ of them presented dysphagia, mostly severe.

In the isolated analysis of each variable, there was no correlation between gender and degree of mental disability concerning the level of dysphagia.

In the analysis of the interaction between age group and the degree of mental disability, we verified that for age groups 
under 30 years old, the higher the degree of mental disability, the higher the odds of severe dysphagia; for the age group between 31 and 40 years old, there was no influence between the degree of mental disability and the severity of the dysphagia; and above 40 years old, the situation reversed, that is, the higher the degree of mental disability, the higher the odds of presenting a less severe dysphagia.

\section{References}

1 Campos JA, Giro EMA, Orrico SRP. Comparação do padrão de alimentação de Portadores com necessidades especiais Institucionalizados e não institucionalizados. Aliment Nutr 2005; 16:273-277

2 Kunigk MRG, Chehter E. Disfagia orofaríngea em pacientes submetidos à entubação orotraqueal. Rev Soc Bras Fonoaudiol 2007; 12:287-291

3 Drozdz DR, Costa CC, Jesus PR, et al. Pharyngeal swallowing phase and chronic cough. Int Arch Otorhinolaryngol 2012;16(04): 502-508

4 Silvério CC, Hernandez AM, Gonçalves MIR. Ingesta oral do paciente hospitalizado com disfagia orofaríngea neurogênica. Rev CEFAC 2010;12:964-970

5 Papadopoulou SL, Exarchakos G, Christodoulou D, Theodorou S, Beris A, Ploumis A. Adaptation and Assessment of Reliability and Validity of the Greek Version of the Ohkuma Questionnaire for Dysphagia Screening. Int Arch Otorhinolaryngol 2017;21(01): 58-65

6 Rosenbek JC, Robbins JA, Roecker EB, Coyle JL, Wood JL. A penetration-aspiration scale. Dysphagia 1996;11(02):93-98
7 Agency for Health Care Policy and Research. Diagnosis and treatment of swallowing disorders (dysphagia) in acute-care stroke patients. Rockville: U. S. Department of Health and Human Services; 1999

8 Langmore SE. History of Fiberoptic Endoscopic Evaluation of Swallowing for Evaluation and Management of Pharyngeal Dysphagia: Changes over the Years. Dysphagia 2017;32(01):27-38

9 Padovani AR, Moraes DP, Mangili LD, Andrade CRF. Protocolo fonoaudiológico de avaliação do risco para disfagia (PARD). Rev Soc Bras Fonoaudiol 2007;12:199-205

10 Macedo Filho ED. Avaliação endoscópica da deglutição (VED) na abordagem da disfagia orofaríngea. Em: Jacobi JS, Levy DS, Silva LMC. Disfagia - Avaliação e Tratamento. 1a ed. Rio de Janeiro: Editora Revinter; 2003:332-342

11 Aurélio SR, Genaro KF, Macedo FED. Análise comparativa dos padrões de deglutição de crianças com paralisia cerebral e crianças normais. Rev Bras Otorrinolaringol 2002;68:167-173

12 Silva RG. A eficácia da reabilitação em disfagia orofaríngea. PróFono R. Atual. Cient 2007;19:123-130

13 Nunes MC, Jurkiewicz AL, Santos RS, et al. Correlation between brain injury and dysphagia in adult patients with stroke. Int Arch Otorhinolaryngol 2012;16(03):313-321

14 Santoro PP, Furia CL, Forte AP, et al. Otolaryngology and speech therapy evaluation in the assessment of oropharyngeal dysphagia: a combined protocol proposal. Rev Bras Otorrinolaringol (Engl Ed) 2011;77(02):201-213

15 Abdulmassih EMS, Filho EDM, Santos RS, Jurkiewicz AL. Evolution of Patients with Oropharyngeal Dysphasia in Hospital Environment. Int Arch Otorhinolaryngol 2009;13(01):55-62

16 Jotz GP. Dysphagia: a symptom to be controlled. Int Arch Otorhinolaryngol 2014;18(02):90-91 